\title{
O CONCEITO DE KINOSTIL \\ e o princípio da montagem no romance \\ Berlim Alexanderplatz, de Alfred Döblin
}

\author{
Elcio Loureiro Cornelsen \\ UFMG
}

\begin{abstract}
RESUMO
O objetivo do presente artigo é apresentar alguns aspectos teóricos postulados pelo escritor alemão Alfred Döblin ao desenvolver sua própria concepção da obra épica na "era da técnica". Tais aspectos contribuem para uma melhor compreensão da relação entre literatura e cinema nas primeiras décadas do século XX.
\end{abstract}

\section{PALAVRAS - CHAVE}

literatura alemã, montagem e cinema, montagem e literatura, literatura e cinema, romance da grande cidade

Quando falamos do papel do cinema na vida e na obra do escritor alemão Alfred Döblin (1878-1957), costumamos recordar alguns episódios e aspectos importantes ao longo da sua trajetória. Foi graças ao cinema, por exemplo, que Döblin, "emigrante" refugiado do nazismo, pôde manter-se durante o exílio norteamericano, atuando como scriptwriter na companhia cinematográfica MetroGoldwyn-Mayer. Outro episódio importante que aproximou Döblin do meio cinematográfico foi a primeira filmagem de sua obra-prima, o romance Berlim Alexanderplatz (1929), ${ }^{1}$ em 1931, cujo roteiro foi escrito pelo autor em parceria com Hans Wilhelm. Porém, o aspecto mais relevante na relação de Döblin com o cinema data de 1913 e está documentado em um ensaio intitulado "An Romanautoren und Ihre Kritiker. Berliner Programm" ["Aos romancistas e seus críticos. Programa berlinense"], uma espécie de manifesto literário em que o autor chama a atenção para a necessidade de um Kinostil ("estilo cinematográfico") no processo de criação romanesca. Aparentemente, este conceito marca o início de um processo que vai se desenvolver por anos, até atingir sua realização prática como princípio estilístico da montagem no romance Berlim Alexanderplatz. Cabe aqui verificarmos de que forma se estabelece a relação entre montagem literária e montagem cinematográfica.

\footnotetext{
${ }^{1}$ Berlin Alexaderplatz. Die Geschichte vom Franz Biberkopf é o único romance de Alfred Döblin, que foi traduzido no Brasil por Lya Luft.
} 


\section{O CONCEITO döbliniano de estilo Cinematográfico (KINOStill) E A PREOCUPAÇÃO COM OS CAMINHOS DO ROMANCE NA ERA NATURALISTA}

Antes de refletirmos sobre o conceito döbliniano de "estilo cinematográfico" (Kinostil), devemos nos indagar primeiramente a respeito do contexto em que ele surge. Em 1913, já existiam 2371 cinemas espalhados por todo o território alemão. O cinema itinerante do início do século tornara-se coisa do passado. A expansão econômica pela qual o cinema vinha passando desde o final da primeira década do século XX tornara-o um ramo industrial independente. Os filmes de curta-metragem, que não contavam histórias e possuíam um caráter documental, foram dando lugar aos filmes de longa-metragem em que figuravam as primeiras estrelas. Naquela época, a linguagem cinematográfica rudimentar começou a desenvolver-se, tornando o cinema apto a contar histórias e, com isso, a atrair cada vez mais público. De acordo com César Guimarães, os filmes compostos de um só plano, em que "o tempo da filmagem coincidia com o tempo da exibição" ("unipontualidade”) - marca dos primórdios do cinema -, começaram a ceder cada vez mais espaço para "filmes compostos pela justaposição de tomadas singulares" ("pluripontualidade"). ${ }^{2}$

A rápida popularização do cinema provocou um acalorado debate em torno de suas conseqüências para a arte e a literatura. Muitos passaram a ver o cinema como concorrente em potencial da obra épica. Vários romancistas levantaram questões sobre a criação poética e as dificuldades de narrar e de representar o mundo moderno. Nomes como Robert Musil, Thomas Mann e Alfred Döblin pertenceram ao grupo daqueles romancistas que não só refletiram sobre os novos caminhos literários a serem seguidos, mas também questionaram os elementos centrais que compunham o modelo romanesco tradicional, como o papel do narrador enquanto instância soberana, a produção da ação linear e a psicologização de caracteres individuais. A partir de então, buscou-se modificar ou mesmo eliminar tais elementos, para que a estética do romance fosse, assim, adequada à realidade empírica do século XX. O cinema passou, então, a ser um referencial, pois acreditava-se que a linguagem cinematográfica, que começava a se desenvolver e a se impor, poderia auxiliar na busca de uma técnica literária mais adequada às transformações do mundo moderno.

Sobretudo nas décadas de 10 e de 20, Döblin procurou contribuir com reflexões acerca dos caminhos da obra épica, num momento em que se anunciava a crise do romance. Suas propostas funcionavam como um apelo aos romancistas, que deveriam deixar de lado os princípios estilísticos do romance do século XIX, para, assim, poderem acompanhar as mudanças de sua época, denominada por Döblin de "era naturalista" (naturalistisches Zeitalter). O objetivo de Döblin — e de vários vanguardistas — era encontrar caminhos que levassem a uma representação adequada à realidade em transformação, sobretudo técnica, e às mudanças resultantes do advento de novas mídias, como o cinema e o rádio. É neste contexto que Döblin sentia-se fascinado pela junção entre arte e técnica, presente no cinema, como possibilidade de reproduzir literariamente a realidade empírica.

${ }^{2}$ Cf. GuIMARÃes. Imagens da memória; entre o legível e o visível, p.113 e seguintes. 
Um fator decisivo na trajetória literária de Döblin, que se associa diretamente ao seu fascínio pela junção entre arte e técnica, foi a sua participação no círculo Der Sturm ("A Tempestade"), formado por escritores e artistas expressionistas em torno de Herwarth Walden, uma das principais figuras da vanguarda artística e literária alemã. Em 1910, juntamente com Döblin, Walden fundou a revista Der Sturm, considerada a principal revista de vanguarda da Alemanha, pois reunia contribuições de expressionistas, futuristas e cubistas. Entre 1910 e 1913, Döblin colaborou com vários artigos, englobando resenhas críticas de literatura, música e teatro. A participação no grupo Der Sturm possibilitou a Döblin o contato tanto com artistas e escritores expressionistas alemães quanto com outros vanguardistas europeus que, a convite de Walden, divulgaram suas propostas e trabalhos em Berlim. O ponto alto do período de existência do círculo Der Sturm foi, sem dúvida, a visita de representantes do futurismo italiano a Berlim em 1912, quando Döblin ficou conhecendo pessoalmente Filippo Tommaso Marinetti, teórico e fundador do grupo futurista, e Umberto Boccioni, um dos principais pintores desse movimento.

A receptividade que Döblin, inicialmente, demonstrou ter em relação ao futurismo italiano deve-se ao fato de que os principais manifestos futuristas, publicados na revista Der Sturm entre março de 1912 e dezembro de 1913, continham alguns conceitos, como movimento, dinamismo e simultaneidade, os quais Döblin pretendia incorporar às suas considerações sobre a obra épica e os caminhos do romance diante das outras expressões artísticas, principalmente a pintura, e diante das novas mídias. Ao se deparar com a arte dos futuristas, Döblin considerou, sobretudo, a técnica progressista no processo de criação artística, reconhecendo nesse movimento um significativo desempenho estético e crítico. A materialidade estética de sua postura artística daquela época coadunava-se, aparentemente, com a dos futuristas. A oposição ao subjetivismo era compartilhada por todos.

Todavia, Döblin não estava de acordo nem com certas exigências futuristas, como, por exemplo, o rompimento radical com o passado e com as tradições artísticas, filosóficas, morais e sociais, nem com o tom radical com que os futuristas enalteciam a guerra. Por fim, o rompimento com Marinetti e os demais futuristas foi inevitável. A gota d'água foi a publicação do manifesto "Die Futuristische Literatur" ("A literatura futurista"), em outubro de 1912, e do "Suplement zum technischen Manifest der Futuristischen Literatur" ("Suplemento do Manifesto Técnico da Literatura Futurista”), em março de 1913, na revista Der Sturm, nos quais Marinetti exigia novas formas de expressão poética na era da máquina:

1. É PRECISO DESTRUIR A SINTAXE COLOCANDO OS SUBSTANTIVOS A OLHO, CONFORME ELES VÃO NASCENDO

2. DeVE-SE USAR O VERBo No INFINITIVO

3. Deve-se Abolir o Adjetivo

4. DeVe-Se Abolir o ADVÉrbio

5. Abolir tambÉm a POntuação 
Na mesma edição em que foi publicado o "Suplemento" de Marinetti, Döblin apresentou o ensaio "Futuristische Worttechnik" ("Técnica futurista das palavras") como uma "Carta Aberta a F. T. Marinetti" - "Offener Brief an F. T. Marinetti" -, em que demonstra a sua rejeição incondicional ao programa literário futurista. $\mathrm{Na}$ sua visão, Marinetti fora longe demais ao tomar o mundo dos "automóveis, aeroplanos e metralhadoras" como a "única realidade", transpondo-a para a literatura. A crítica a esse manifesto é formulada por Döblin a partir da crença de que a linguagem seria um meio de aproximação à realidade; destruí-la significaria distanciar-se da realidade. Por fim, Döblin deixa claro a Marinetti que ele pretende seguir o seu próprio caminho literário: "Cuide do seu futurismo. Eu cuido do meu döblinismo".

No entanto, isso não significa que Döblin, a partir de então, rejeitaria totalmente o futurismo. A descrição dinâmica da cidade em franca transformação técnica e a admiração diante dos progressos técnicos e da grande cidade como forma típica de aglomeração humana na "era naturalista" faz-nos lembrar do modo dinâmico como Marinetti enaltece a técnica e a grande cidade no seu "Manifesto do Futurismo".

O "Programa berlinense", última contribuição crítica de Döblin para a revista Der Sturm, surge em resposta ao manifesto literário dos futuristas. Nele, Döblin expôs alguns postulados que compunham, naquela fase, o seu "döblinismo", uma espécie de estética autônoma que o autor reclamava para si. A partir do texto, podemos destacar quatro conceitos centrais que nos permitem estabelecer uma relação entre literatura e cinema: "estilo cinematográfico" (Kinostil), "despersonalização" (Depersonation), "fantasia factual" (Tatsachenphantasie) e "fantasia cinética" (kinetische Phantasie).

No seu manifesto, Döblin propõe uma reflexão sobre um dos fundamentos da literatura: a capacidade de emitir imagens por meio de palavras. Segundo Döblin, o fator determinante das imagens é o seu meio, a grande cidade, o berço da técnica que exige do olhar do poeta uma nova forma de apreensão diante da multiplicidade de imagens e sons e uma nova forma de expressão da avalanche dessas imagens em um movimento incessante:

Com a enorme quantidade de coisas a serem moldadas, a representação exige um estilo cinematográfico. ${ }^{4}$

Como definição para o conceito de Kinostil, com o qual os demais conceitos estão intimamente ligados, Döblin considera a seqüência rápida e contínua de imagens que, ao ser transposta para o campo literário, poderia proporcionar ao autor épico a criação do efeito de simultaneidade, apesar da linearidade do discurso escrito:

O todo não deve aparecer como falado, mas sim como existente. ${ }^{5}$

Döblin baseia-se no estilo simultâneo dos primórdios do cinema, em que havia a ausência de ornamentação e um certo comedimento das imagens, além do dinamismo. O "estilo cinematográfico" é apresentado como um estilo de construção por excelência:

\footnotetext{
${ }^{3}$ DöBlin. Futuristische Worttechnik. Offener Brief an F. T. Marinetti, p.119. (Tradução minha).

${ }^{4}$ Döblin. An Romanautoren und ihre Kritiker. Berliner Programm, p.121. (Tradução minha).

${ }^{5}$ DöBlin. An Romanautoren und ihre Kritiker. Berliner Programm, p.122. (Tradução minha).
} 
não se narra, se constrói. ${ }^{6}$

Portanto, tal estilo deveria ser fruto de um narrador que narra menos e constrói mais. Além disso, a hegemonia do autor deveria dar lugar à independência do leitor do romance:

quem deve julgar é o leitor, e não o autor.?

Não é por acaso que Döblin associa ao conceito de Kinostil uma postura antipsicológica que deveria marcar a redução da intervenção do autor, em que o narrador autorial torna-se dispensável. Tal postura é definida por ele como "despersonalização" (Depersonation). Acreditava que o romancista poderia assumir uma postura perante a realidade, em que este exerceria a mera função de descrever o mundo à sua volta e os acontecimentos, sem interferir na narrativa por meio de reflexões subjetivas:

eu não sou eu, mas a rua, os candeeiros, este e aquele acontecimento, nada além. ${ }^{8}$

Seria necessário ativar tanto a "fantasia factual" (Tatsachenphantasie) quanto a "fantasia cinética" (kinetische Phantasie) para produzir o efeito de objetividade na representação do suposto "real". Também seria privilegiada uma perspectiva múltipla, ao invés da focalização de um único herói e de sua representação a partir de uma perspectiva central, como era o caso do romance de formação no século XIX. O narrador precisaria diluir-se na objetividade, a fim de atingir uma postura estéticofilosófica que Döblin chamava de "naturalismo":

O naturalismo não é um 'Ismo' histórico, mas um aguaceiro que sempre cai sobre a arte, e que deve continuar caindo. $\mathrm{O}$ psicologismo, o erotismo precisa ser levado com a enxurrada. Auto-desapropriação, renúncia do autor, despersonalização. A terra precisa ferver novamente. Libertemo-nos do homem! Coragem para a fantasia cinética e para o reconhecimento dos contornos reais inacreditáveis! Fantasia factual! O romance precisa vivenciar o seu renascimento como obra de arte e epopéia moderna. ${ }^{9}$

O naturalismo, como tendência estética na literatura, que se desenvolveu do positivismo entre 1870 e 1900, não deve ser confundido com o naturalismo teóricoliterário e filosófico de Alfred Döblin. Afinal, não se trata aqui de um anacronismo, ou seja, Döblin não prega uma reabilitação do naturalismo. Mais do que isso, sua teoria resulta de uma continuidade de fundamentos estéticos naturalistas, os quais são, em parte, complementados por outros fundamentos e, em parte, modificados.

As considerações de Döblin sobre a "despersonalização" lembram a forma como Arno Holz (1863-1929), escritor e principal teórico do naturalismo alemão, postulou a "matematicidade" da arte através da fórmula "Arte $=$ Natureza $-\mathrm{x}$ " (Kunst $=$ Natur $-x) " .{ }^{10} \mathrm{~A}$ proximidade entre a definição döbliniana de

\footnotetext{
${ }^{6}$ DöBlin. An Romanautoren und ihre Kritiker. Berliner Programm, p.122. (Tradução minha).

${ }^{7}$ DöBlin. An Romanautoren und ihre Kritiker. Berliner Programm, p.121. (Tradução minha).

${ }^{8}$ Döblin. An Romanautoren und ihre Kritiker. Berliner Programm, p.122. (Tradução minha).

${ }^{9}$ DöBlin. An Romanautoren und ihre Kritiker. Berliner Programm, p.123. (Tradução minha).

${ }^{10}$ Holz. Die Kunst. Ihr Wesen und ihre Gesetze, p.171.
} 
"naturalismo" e a do naturalismo literário é patente em seu ensaio "Programa berlinense". A "fantasia factual" (Tatsachenphantasie), a "despersonalização" (Depersonation) e o "psicologismo" (Psychologismus), termos associados ao conceito de "estilo cinematográfico" (Kinostil), indicam o parentesco da teoria poética döbliniana com os postulados literários dos naturalistas. Pois a "fantasia factual" contém em si duas dimensões contrárias e ao mesmo tempo complementares: de um lado, o poder da liberdade de criação, de outro, a realidade factual impondo limites a essa liberdade por meio do emprego de materiais e temas autênticos. Trata-se, portanto, de um meio-termo entre a fantasia criativa e a realidade enquanto fonte de criação. A “despersonalização" defendida por Döblin também estaria de acordo com a meta dos naturalistas, que acreditavam que a fórmula "Arte = natureza $-\mathrm{x}$ " poderia ser reduzida à formula "Arte = Natureza". Em contraponto, a "abstração", a partir da influência da pintura expressionista sobre a literatura, e o "psicologismo", por um lado, eliminariam a Natureza da fórmula e, por outro, causariam uma supervalorização do "x", de modo que teríamos "Arte $=\mathrm{x}$ ", e " $\mathrm{x}$ " significaria aqui a tentativa do artista de expressar seu mundo interior através da abstração e do total afastamento da realidade objetiva. Com isso, o fator "x" da fórmula de Holz, quer dizer, o conjunto de condições de reprodução da realidade por meios literários, na teoria de Döblin, não é o objetivo, mas sim o meio que exerce sua função de modo eficaz, na medida em que revela na obra de arte a Natureza como ela supostamente "é".

O protesto de Döblin contra a "desrealização" da realidade por meio da total "abstração" e do "psicologismo" resulta, afinal, do reconhecimento de que o desprezo pela realidade conduz à supervalorização do abstrato, que, por sua vez, não é mais atrelado à realidade. De acordo com Döblin, que, de modo recorrente, alude a Homero como o grande épico, a essência do estilo épico consiste na descrição e na enumeração dos fatos, em que o autor-narrador se "despersonaliza", isto é, não tece comentários e nem faz qualquer tipo de interferência de ordem psicológica. Para isso, o autor-narrador deveria aprender a lidar com a realidade através da psiquiatria, que propõe a mera observação e a descrição dos acontecimentos, processos e movimentos, sem traçar conclusões, comentários ou análises. Ao atacar o psicologismo, Döblin propõe o exemplo do psiquiatra que "se limita a anotar o decurso, os movimentos, com um dar de ombros pelo 'mais', o 'porquê' e o 'como'”. ${ }^{11}$ A perspectiva do médico psiquiatra ${ }^{12}$ e a do romancista fundem-se: o autor épico deve diagnosticar, e não apresentar reflexões de ordem subjetiva. Döblin apontava essa forma despersonalizada do autor como condição sine qua non para a concretização de um "estilo cinematográfico" na obra épica. Porém, é evidente que se trata de uma ilusão crer que a instância criadora — tanto o autor quanto o realizador - possa se "despersonalizar" totalmente a ponto de reproduzir a

\footnotetext{
${ }^{11}$ DöBlin. An Romanautoren und ihre Kritiker. Berliner Programm, p.121.

${ }_{12}$ Döblin estudou medicina entre 1900 e 1905, especializando-se em neurologia e psiquiatria. Inicialmente, atuou como neurologista em alguns manicômios e sanatórios. Em 1911, abriu uma clínica particular para pacientes da Previdência. Sua carreira médica encerrou-se em fevereiro de 1933, quando Döblin, por motivos de sobrevivência, viu-se forçado a deixar a Alemanha nazista, iniciando, assim, um longo período de exílio.
} 
realidade tanto literária quanto cinematograficamente. O filme documentário demonstra-nos isso, pois, sendo um "recorte" da realidade, pressupõe julgamento e escolha por parte do realizador para efetuar tal "recorte".

No que diz respeito ao conceito de técnica, Döblin diferenciava-se dos futuristas italianos por não ver sentido na técnica em si mesma. Para ele, a técnica era a expressão do homem moderno. Se transportarmos essa visão para o modo como Döblin associa o conceito de Kinostil ao conceito de Depersonation, temos dois pontos importantes na sua teoria da obra épica: de um lado, a idéia de movimento e, de outro, a idéia de realidade imediata que devem ser reproduzidas pelo romancista. Nos primórdios do cinema, segundo Jean-Claude Bernadet, a "impressão da realidade" ${ }^{13}$ impôs-se graças à produção de imagens em movimento, mesmo não passando de mera ilusão produzida tecnicamente, ou seja, a ilusão de "uma arte objetiva, neutra, na qual o homem não interfere", que era fundada na crença de que a "mecânica elimina a intervenção e assegura a objetividade". Da mesma forma, Walter Benjamin chama a atenção para o fato de que

a realidade, aparentemente depurada de qualquer intervenção técnica, acaba se revelando artificial, e a visão da realidade imediata não é mais que a visão de uma flor azul no jardim da técnica. ${ }^{14}$

Originalmente, podemos dizer que, para Döblin, o mais importante era aquilo que Luiz Nazário aponta como sendo a verdadeira natureza do filme, ou seja, a "imagem-em-movimento-ela-mesma", e não o "registro mecânico do movimento das coisas", fazendo jus ao significado da palavra grega kinema, "movimento". ${ }^{15}$ Também não era intenção de Döblin enfatizar o caráter técnico do cinema. Para ele, o movimento significava o movimento em si, e não a impressão de movimento de uma imagem produzida pela projeção seqüencial de vinte e quatro fotogramas por segundo.

\section{Do CINEMA PARA a literatura: a MONTAgem DÖBLINIANA E O ROMANCE BERLIM ALEXANDERPLATZ}

Quando falamos de Döblin e de sua obra, vemo-nos necessariamente obrigados a mencionar dois aspectos importantes: o primeiro é o reconhecimento de que Döblin inscreveu o seu nome no grupo daqueles romancistas que se destacaram nas primeiras décadas do século XX por terem empregado novas técnicas no processo de representação da realidade urbana, como James Joyce e John dos Passos; o outro diz respeito à técnica empregada até as últimas conseqüências no romance Berlim Alexanderplatz: a montagem.

O conceito de montagem, originário do âmbito industrial, ganhou significado especial com o cinema no processo de composição do filme. Entre 1910 e 1928, período que vai desde o momento em que se começa a desenvolver experiências que tornarão o cinema apto a criar uma linguagem própria até o advento do cinema sonoro, marcado

\footnotetext{
${ }^{13}$ Bernadet. O que é cinema, p.15 e seguintes.

${ }^{14}$ Benjamin. A obra de arte na era de sua reprodutibilidade técnica, p.186.

${ }^{15}$ NAZÁrio. Contra o cinema conceitual, p.94.
} 
pela exibição do filme norte-americano The jazz singer, a maior conquista em termos de linguagem foi a montagem como processo de manipulação que pressupõe a seleção e a ordenação de imagens em uma determinada seqüência.

A técnica de montagem cinematográfica, desenvolvida nas primeiras décadas do século XX, costuma ser relacionada a três nomes: o cineasta norte-americano David Wark Griffith (1875-1948) e os cineastas soviéticos Vsevolod Illarionovich Pudovkin (1893-1953) e Sergei Mikhailovich Eisenstein (1898-1948). Certamente, Griffith ajusta-se plenamente à temática em discussão, ou seja, a relação entre literatura e cinema, pois Griffith alegou ter encontrado inspiração para o desenvolvimento e o emprego da técnica de montagem nada mais nada menos que em Charles Dickens (1812-1870). Para ele, Dickens apresentava em suas obras quadros realistas que possibilitavam ao leitor uma confrontação não apenas com o mundo descrito e a ação, mas também com uma forma toda especial de criar a sensação de som, cheiro, cor, etc. Griffith também chamou a atenção para o fato de que Dickens criava tensão ao alternar quadros de episódios que iam desenvolvendose paralelamente. Não se pode dizer que isto tenha sido algo praticado apenas por Dickens na literatura. Porém, foi justamente a leitura de Dickens que inspirou Griffith a desenvolver a "montagem paralela" (chamada por ele de switchback), que também pretendia ser uma técnica que criaria tensão e suspense. Um exemplo de "montagem paralela" criada por Griffith e destacada por Sergei Eisenstein ${ }^{16} \mathrm{em}$ um ensaio sobre o cineasta norte-americano é a seqüência de cenas no filme Enoch Arden, de 1911, em que Griffith alterna as imagens de uma mulher solitária, em casa, pensando no marido desaparecido, com as imagens do marido, sobrevivente de um naufrágio, em uma ilha deserta, pensando na família distante.

Griffith também empregou uma estrutura similar à da "montagem paralela" para criar um efeito diferente do suspense, como aponta Tom Gunning: no filme de curtametragem A corner in wheat (1909), Griffith contrasta, por meio da montagem, a prosperidade de um rico produtor de trigo com o sofrimento que este causa aos fazendeiros e aos pobres. Não se trata, pois, de um mero contador de histórias alternando as imagens para criar suspense, mas da criação de uma voz moralizante que intervém na narrativa para que o espectador tire conclusões em relação ao contraste apresentado, de fundo ideológico, em uma espécie de julgamento moral. ${ }^{17}$

Sem dúvida, com o desenvolvimento da "montagem paralela" durante o período em que dirigiu filmes para a companhia cinematográfica Biograph, entre 1908 e 1913, Griffith inaugurou uma tradição de cineastas que não só valorizavam a montagem como técnica de criação de suspense, mas também de significação. A concepção de montagem de Pudovkin, por exemplo, aproxima-se da de Griffith: para Pudovkin, a montagem é um princípio de combinação de planos formando um bloco seqüencial, em que se pode criar, por exemplo, o efeito de tensão e significação. Pudovkin destaca a montagem como a "ligação" de planos em série, para se expor uma idéia. Em uma experiência feita em parceria com o cineasta Lev Kulechov no ano de 1919, Pudovkin

\footnotetext{
${ }^{16}$ Cf. Eisenstein. Dickens, Griffith e nós, p.177.

${ }^{17}$ Cf. GunNing. Weaving a Narrative; style and economic background in Griffith's biograph films, p.341 e seguintes.
} 
demonstrou o efeito da montagem na significação das tomadas individuais: uma única tomada do rosto do ator russo Mosjukhin foi intercalada com outras três tomadas um prato de sopa, um caixão, no qual jazia uma mulher morta, e uma criança brincando. Ao serem indagados após a exibição da seqüência montada, os espectadores elogiaram o desempenho do ator ao expressar fome diante do prato de sopa, dor diante do cadáver e felicidade diante da imagem da criança brincando. No entanto, a tomada do rosto de Mosjukhin era a mesma. Com isso, Pudovkin e Kulechov concluíram que imagens isoladamente neutras, ao serem associadas, podem produzir significação a partir do efeito sobre o espectador. ${ }^{18}$

Por fim, considera-se que o cineasta Sergei Eisenstein foi o primeiro a definir e a empregar a montagem, de maneira conseqüente, como um processo em que dois textos quaisquer são alinhados, unindo-se necessariamente em uma nova idéia. Nos anos 20, Eisenstein procurou empregar a montagem em um sentido que ia além das concepções de Griffith e de Pudovkin: enquanto Griffith desenvolveu a "montagem paralela" como uma prática que deveria produzir tensão ou contraste entre histórias narradas paralelamente, e enquanto Pudovkin destacava a montagem como a "ligação" de planos em série que produz uma idéia, mas ainda sem significar uma fissura na continuidade da narrativa cinematográfica, Eisenstein compreende a montagem como uma "colisão", um conflito de duas peças entre si. ${ }^{19} \mathrm{Com}$ isso, a montagem é deslocada do plano da ação para o da significação, em que a significação não é construída a partir de planos que ainda estabelecem uma relação de continuidade, como na experiência de Pudovkin e Kulechov. A montagem eisensteiniana quer mais do que criar suspense ou contraste: ela pretende explicitar significação naquilo que Eisenstein chama de "contextos e séries 'intelectuais". ${ }^{20}$ No filme A greve (Statchka, 1925), por exemplo, o fuzilamento em massa dos grevistas é entrecortado por cenas que retratam o matadouro da cidade. Por meio de "justaposição", Eisenstein transforma imagens aparentemente dissociadas em termos de ação "numa metáfora cinematográfica de 'um matadouro humano", ${ }^{21} \mathrm{em}$ que o assassinato dos trabalhadores não é representado apenas pela ação, mas potencializado pela plasticidade do sangrento matadouro.

Paralelamente ao desenvolvimento da técnica de montagem cinematográfica, a montagem como técnica literária adquiriu significado nas primeiras décadas do século XX e esteve no centro dos debates que diziam respeito à superação das convenções da narrativa ficcional até então vigentes. Freqüentemente, a técnica de montagem também apresentava-se como tema em comum com a problemática em torno da grande cidade, pois a mudança de percepção da realidade empírica imposta pela industrialização e a urbanização, com todas as implicações técnicas que estavam surgindo na época, eram tidas como o fator que causou o surgimento de técnicas como a montagem e a colagem. Pesquisas apontam a montagem literária como conceito principal, enquanto colagem seria apenas um tipo específico de

\footnotetext{
${ }^{18}$ Cf. Pudovkin. Filmtechnique, p.140.

${ }^{19} \mathrm{Cf}$. Eisenstein. Fora de quadro, p.41.

${ }^{20}$ EIsenstein. Fora de quadro, p.36.

${ }^{21}$ Pudovkin. Filmtechnique, p.210.
} 
montagem. Certo é que montagem, no sentido literário, de acordo com Viktor Zmegac, associa-se ao uso de textos ou segmentos de textos que são integrados em um novo texto preexistente. ${ }^{22}$ Em contraponto, colagem seria um caso extremo de montagem, um pólo surreal, quando um novo texto é construído exclusivamente a partir de segmentos de outros textos. Em oposição às convenções da poética mimética, que geralmente encobre a construção, a montagem explícita é apresentada abertamente, sinalizando onde os textos montados começam e onde acabam, como os textos se fixam e como funcionam isoladamente entre si.

No caso do emprego da montagem literária, Döblin não foi um pioneiro. A montagem literária já havia sido praticada na literatura alemã por Georg Büchner (1813-1837) no drama A morte de Danton (Dantons Tod, 1835), em que o autor une ficção e fatos históricos relativos à Revolução Francesa e às suas conseqüências por meio da montagem de discursos documentados e de depoimentos autênticos de personagens históricos, que reforçam o teor realista da obra. A inovação vanguardista no emprego da montagem não se situava em apagar os contornos dos segmentos montados, como no caso de A morte de Danton, mas de marcar claramente onde a parte montada começa e termina, e, sem dúvida, como tal parte funciona em relação ao texto que ela passa a integrar e em relação a demais textos montados. Através da técnica da montagem literária no sentido vanguardista, cujo princípio formal é a heterogeneidade das partes, o autor apresenta o mundo como espaço de elementos heterogêneos simultaneamente presentes.

As raízes da montagem döbliniana estão documentadas no "Programa berlinense". Como vimos, Döblin concebia o "estilo cinematográfico" como um estilo realizado a partir da "despersonalização" do autor, despojado de qualquer "subjetivismo", e tendo como alicerces a "fantasia cinética" — na representação das mais diversas sensações - e a "fantasia factual", que, necessariamente, atrelava a criação à realidade empírica.

Curiosamente, as modificações que se processaram na teoria da obra épica de Döblin entre 1913 e 1929, no que diz respeito ao conceito de Kinostil, parecem acompanhar certas transformações na linguagem cinematográfica. Ao "Programa berlinense" seguiram-se outros quatro ensaios: "Notas sobre o romance" ("Bemerkungen zum Roman", 1917), "Sobre romance e prosa" ("Über Roman und Prosa", 1917), "Reforma do romance" ("Reform des Romans") e "A construção da obra épica" ("Der Bau des epischen Werks", 1929). Enquanto os três primeiros ensaios reiteram os tópicos defendidos no "Programa berlinense", sem, no entanto, exibirem novamente o conceito de Kinostil, o último, concebido por Döblin durante o processo de criação do romance Berlim Alexanderplatz, revela uma mudança fundamental no modo de interpretar a instância do autor:

O autor pode tomar a palavra na obra épica? Ele pode saltar para dentro desse mundo? Resposta: sim, ele pode, deve e precisa. ${ }^{23}$

\footnotetext{
${ }^{22}$ ZMEGAC. Montage/collage, p. 259.

${ }^{23}$ DöBlin. Der Bau des epischen Werks, p.536. (Tradução minha).
} 
Deste modo, a "despersonalização" - e, com ela, o "estilo cinematográfico" é redimensionada, pois a interferência do autor agora é bem-vinda, se bem que Döblin não vê tal interferência como aspecto que emprestaria à obra épica um caráter subjetivo, mas como resultado da liberdade que o autor deve ter no processo de criação:

Os senhores levarão as mãos à cabeça, por eu aconselhar os autores a serem decididamente líricos, dramáticos, e reflexivos na obra épica. Mas eu insisto nisso. ${ }^{24}$

Aquela idéia que parecia originar-se dos primórdios do cinema, em que a ilusão da realidade criada pela impressão das imagens em movimento sobrepujava o caráter eminentemente técnico com que essas mesmas imagens eram produzidas e projetadas, é substituída por outra que tem em seu centro o autor com plenos poderes para criar, poderes esses, aliás, outorgados não por uma instância que atua fora do processo de criação, mas pelo próprio tema:

Eu convido a que façam da forma épica uma forma totalmente livre, para que o autor possa seguir todas as possibilidades de representação que o seu tema requer. ${ }^{25}$

A realidade imagética, na teoria de Döblin, deve ser abstraída a partir da realidade discursiva. Diferente do realizador que registra as imagens através da câmera, o escritor dispõe da realidade discursiva, ou seja, da linguagem em si e de toda uma gama de produções discursivas, nas quais estão fixadas as mais diversas imagens que compõem tanto os vários registros da realidade empírica como o incomensurável arquivo da tradição fixada pela escrita. Os cortes, neste caso, são segmentações de textos que, ao serem integrados em um outro texto, estabelecem uma relação de contigüidade ou de conflito. Döblin tinha plena consciência da reprodução discursiva no processo de enunciação:

cremos falar e somos falados, ou cremos escrever e somos escritos. ${ }^{26}$

Enquanto instância, o leitor também é redefinido por Döblin: agora, não se trata apenas de um leitor que detém o livre poder de julgar, proporcionado pela diluição do autor despersonalizado, mas especificamente do leitor do romance escrito segundo o princípio da montagem, que compartilha do processo de produção da obra ao participar ativamente, fazendo associações, orientadas previamente por meio de marcas contidas no(s) texto(s):

O leitor realiza, portanto, o processo de produção juntamente com o autor. ${ }^{27}$

Segundo Döblin, o leitor vivencia a obra épica in statu nascendi. O verdadeiro "herói" da montagem é o leitor que estabelece as relações contidas no texto montado. Não se trata, portanto, de uma narrativa em sentido tradicional, pois exige do leitor outras formas de percepção que garantam a coerência (inter)textual. A ressonância

\footnotetext{
${ }^{24}$ DöBlin. Der Bau des epischen Werks, p.535. (Tradução minha).

${ }^{25}$ Döblin. Der Bau des epischen Werks, p.536. (Tradução minha).

${ }^{26}$ Döblin. Der Bau des epischen Werks, p.550. (Tradução minha).

${ }^{27}$ DöBlin. Der Bau des epischen Werks, p.540. (Tradução minha).
} 
aparece como princípio textual: o leitor realiza, através de associações, a significação dos textos. Se, por exemplo, um texto é montado juntamente com outro, surge um terceiro texto cujo conteúdo é resultado da soma dos textos isolados. Tal procedimento implica mudanças de ponto de vista, semelhantes às mudanças que a câmera proporciona em um filme, pois o autor-narrador despersonalizado desaparece em meio à polifonia resultante de várias vozes e de textos do cotidiano. Isto torna-se possível na medida em que a montagem destrói a identidade do eu como instância subjetiva. A montagem como meio desencadeador de mudança contínua de perspectiva produz o efeito de simultaneidade. Deste modo, o Kinostil torna-se definição da representação multiperspectiva do mundo.

Döblin concebia a montagem como um pólo construtivo, do mesmo modo como afirmara no ensaio de 1913 que o autor constrói mais do que narra. Segundo ele, o autor épico censura, altera, combina, varia. De modo diferente da narrativa linear, os elementos no texto montado assumem uma função paradigmática. Os elementos da montagem criam um espaço textual anônimo, no qual se desenrola a história. A rede formada por textos montados simula, de maneira exemplar, a atividade inconsciente de apreensão que um transeunte, por exemplo, realiza, movendo-se apressado, bem ao ritmo urbano da grande cidade. Tal procedimento acarreta a formação de uma totalidade discursiva descontínua. $\mathrm{O}$ mundo apresenta-se a Döblin como um mundo de linguagens e textos, que impele o romancista a renunciar à continuidade. A disposição de uma "memória coletiva" de textos sob influência lingüística, cultural e histórica faz com que a técnica de montagem literária delimite espacialmente a linguagem, a memória, a psique como uma cidade de palavras e textos, transformando o espaço textual em espaço urbano, em que o sujeito permanece anônimo, despersonalizado.

A montagem como técnica literária baseia-se no processo de integração de textos literários com textos considerados extra-literários (por exemplo, manchetes de jornal, textos publicitários, documentos históricos) ou com citações ou paráfrases de outros textos literários. O autor-narrador que adota esse princípio surge como artesão, um montador que realiza o processo de criação por meio de diversos materiais, em que sua "fantasia" trabalha a partir de "fatos" textuais — o que demonstra a validade do conceito de Tatsachenphantasie, ainda no ensaio de 1929 —, e não exclusivamente através do "gênio" criativo do autor.

A concepção de montagem literária döbliniana aproxima-se mais da idéia que Sergei Eisenstein tinha da montagem cinematográfica: ela não se destina apenas à criação de suspense, como no caso da "montagem paralela" em Griffith, mas à produção de uma rede de associações, construída a partir de planos montados, que, em geral, criam o efeito metafórico por meio de tais associações. A manutenção da continuidade da ação em uma seqüência montada, como em Griffith e Pudovkin, também não é o seu objetivo. Em contraponto, o conceito eisensteiniano de colisão parece aproximarse mais da forma como Döblin concebe o princípio da montagem como fator de descontinuidade. É importante salientar, também, que Eisenstein atribuía ao espectador — da mesma forma que Döblin em relação ao leitor do romance — uma participação na realização da obra cinematográfica: 
A força da montagem reside nisto, no fato de incluir no processo criativo a razão e o sentimento do espectador. O espectador é compelido a passar pela mesma estrada criativa trilhada pelo autor para criar a imagem. O espectador não apenas vê os elementos representados na obra terminada, mas também experimenta o processo dinâmico do surgimento e reunião da imagem, exatamente como foi experimentado pelo autor. ${ }^{28}$

O romance Berlim Alexanderplatz é o exemplo típico dessa realização da obra por parte do recipiente - no caso, o leitor. No lugar de uma narrativa linear, entra em cena um estilo comparável ao da montagem no cinema. A grande cidade é montada através de um emaranhado de textos que se entrecruzam na história do protagonista Franz Biberkopf.

Döblin concebeu o romance Berlim Alexanderplatz como uma obra que deveria apresentar o panorama berlinense na República de Weimar. A imagem de Berlim surge através da montagem de inúmeros fragmentos da realidade cotidiana: trechos de relatórios da Bolsa de Valores, publicações oficiais, anúncios, reclames, murais, prospectos cinematográficos, cartas de presidiários, estudos estatísticos, notícias locais, artigos extraídos de enciclopédia, sucessos musicais da época, canções marciais, previsões do tempo, matérias sobre escândalos, citações e paráfrases do texto bíblico, itinerários de bondes, etc. O desemprego, a atmosfera de pequenos bares e o submundo do crime compóem o enredo. Nos anos 20, a Alexanderplatz era uma praça que representava o ponto de cruzamento dos proletários que viviam na parte oriental da cidade. Um deles é o ex-presidiário Franz Biberkopf, que, após ter cumprido quatro anos de reclusão pelo espancamento seguido de morte de sua namorada e prostituta, quer recomeçar a vida como homem honesto. No entanto, o submundo o atrai. Por três vezes, Biberkopf é atingido por "golpes do destino" que o destroem, até que ele, em um lance inusitado, acaba indo parar em um manicômio, onde morre e, ao mesmo tempo, renasce como um novo Franz Biberkopf.

O romance Berlim Alexanderplatz foi construído em dois planos: no plano de ação, desenrola-se a história de Franz Biberkopf, intercalada com os mais variados textos (conforme já mencionado, reclames, textos publicitários, trechos de matérias de jornal, notas sobre a previsão do tempo, canções populares, canções marciais, itinerários, discursos políticos, etc.); o outro plano compõe-se de fragmentos bíblicos (citações de trechos do Eclesiastes, do Livro de Jeremias, paráfrases do Gênesis, do Livro de Éster, versão do Livro de Jó, a criação de personagens, como a figura alegórica da morte e a imagem apocalíptica da "Babilônia Prostituta", extraída do Apocalipse, etc.) e literários (por exemplo, citações extraídas das obras Der Prinz von Homburg (1821), de Heinrich von Kleist, e Iphigenie auf Tauris (1786), de Goethe). Enquanto o primeiro plano apresenta-se a partir de uma linha marcadamente históricocronológica, o segundo adquire um caráter mítico-religioso. As ações de ambos os planos ora entrecruzam-se, ora desenrolam-se separadamente uma da outra, mas estão em uma estreita relação.

${ }^{28}$ EISENSTEIN. Palavra e imagem, p.27. 
Através do princípio estilístico da montagem, Döblin não apenas constrói a cidade de Berlim por meio de textos, mas também insere a história de Franz Biberkopf em um contexto maior, de caráter existencial, em que as experiências individuais do protagonista são apresentadas de uma outra forma, na medida em que são relacionadas, por meio de associação, ao plano mítico-religioso, formando uma espécie de "canto paralelo", de dimensão paradigmática. Desta forma, a história de Franz Biberkopf deixa de ter um sentido individual para ganhar um sentido exemplar, aludido pela suspensão temporal do plano mítico-religioso. A esfera do cotidiano mescla-se com a esfera mítico-religiosa, ora para confrontar as experiências de Biberkopf com um plano elevado, ora para demonstrar, em tom profético, as atitudes que o protagonista tem de assumir para entender o sentido da vida a partir de uma nova postura.

A renúncia à causalidade pode, em um primeiro momento, sugerir o arbitrário, ou seja, a intencionalidade do autor de dar expressão a um suposto caos da grande cidade. Todavia, a leitura atenta revela uma rede de interdependências e de ressonâncias entre a grande cidade e Biberkopf. Através da técnica de montagem, Döblin torna presente a totalidade do mundo, e não apenas o pequeno mundo do protagonista. A montagem dos mais diversos textos limita-o, pois sua história não apresenta a totalidade do mundo, mas é a plenitude caótica do mundo que interrompe continuamente sua história.

A título de exemplo do emprego da montagem döbliniana, selecionamos duas passagens do romance Berlim Alexanderplatz. No início do Segundo Livro, de um total de nove livros que compõem o romance, a ingenuidade de Biberkopf em acreditar que a grande cidade, do mesmo modo que a prisão, orientaria-se por uma »ordem «, que ele deveria observar a fim de evitar problemas, é expressa por meio de uma seqüência de textos montados:

Uma vez viveram no paraíso duas pessoas, Adão e Eva. Tinham sido colocadas ali pelo Senhor, que também fez animais e plantas e céu e terra. E o paraíso era o belíssimo jardim do Éden. Flores e árvores cresciam ali, animais brincavam por toda parte, ninguém atormentava ninguém. $\mathrm{O}$ sol nascia e se punha, e a lua fazia o mesmo, o dia todo era festa no paraíso.

Assim começaremos alegremente. Vamos cantar e nos mexer: com as mãozinhas palma, palma, palma, com os pezinhos, pé, pé, pé, uma vez pra lá, uma vez pra cá, uma voltinha, isso é o que dá!

Franz Biberkopf entra em Berlim ${ }^{29}$

Ao título "Franz Biberkopf entra em Berlim", segue-se a apresentação de alguns símbolos de órgãos municipais e de seus respectivos nomes, como "Comércio e indústria", "Limpeza urbana e transportes", "Serviço de saúde", "Companhia de gás", "Corpo de bombeiros", "Finanças e impostos", etc. ${ }^{30}$ Se traçarmos uma analogia entre o processo de montagem de Eisenstein, em que dois textos quaisquer são alinhados, unindo-se necessariamente em uma nova idéia, e a construção dessa passagem do romance Berlim Alexanderplatz, poderíamos dizer que a paráfrase de versículos do Gênesis 1-3 e o trecho

\footnotetext{
${ }^{29}$ DöBlin. Berlim Alexanderplatz; a história de Franz Biberkopf, p.43.

${ }^{30}$ DöBlin. Berlim Alexanderplatz; a história de Franz Biberkopf, p.43 e seguintes.
} 
da ópera infantil Joãozinho e Maria (Hänsel und Gretel, 1893), de Engelbert Humperdinck, construídas em seqüência, expressam metaforicamente o estado em que se encontra Biberkopf no momento em que adentra a cidade que, também metaforicamente, apresenta suas "armas" ao ingênuo e alegre "conquistador". No entanto, na medida em que os contratempos vão surgindo, o quadro da harmonia paradisíaca e da alegria infantil desfaz-se textualmente de modo fragmentário: "Bater as mãozinhas, palma, palma, palma, e os pezinhos, pé, pé, pé, peixes, pássaros, o dia todo, paraíso." 31

Passagens como estas emprestam plasticidade à história de Franz Biberkopf e, ao mesmo tempo, tornam a narrativa descontínua. São patentes os contornos de tais fragmentos montados de maneira justaposta.

O segundo e último exemplo de montagem döbliniana em Berlim Alexanderplatz também remete-nos às estratégias de Eisenstein no filme A greve. Do mesmo modo que o cineasta soviético lançou mão da imagem de um matadouro para potencializar cinematograficamente as cenas de violência imposta aos trabalhadores revoltosos, Döblin também intercala na história de Biberkopf um texto que descreve o matadouro de Berlim:

Um grande touro branco é levado para o galpão de abate. Aqui não há vapor, nem
baia como para os porcos fervilhantes. O grande animal poderoso, o touro, passa
sozinho pelo portão entre os homens que o tangem. O local, ensangüentado, está
aberto diante dele com as metades e quartos pendurados, os ossos picados. O grande
touro tem testa larga. Ele é impelido diante do carniceiro com varas e empurrões.
Para que fique mais bem colocado, o homem ainda lhe dá um leve golpe com a
parte rombuda do machado, de lado na perna traseira. Agora um dos tangedores
agarra o touro por baixo no pescoço, o animal pára, cede, cede com singular
facilidade, como se concordasse e aquiescesse, depois de ter visto tudo e saber: este
é o meu destino, e não há nada a fazer. Talvez ele considere o gesto do homem uma
carícia, pois parece tão amável. Segue o braço do homem que o puxa, inclina a
cabeça, focinho para cima. ${ }^{32}$

A seqüência do matadouro encerra-se com uma voz desconhecida que interpela Biberkopf, sem que este a ouça. Apenas no final do romance é que o leitor toma conhecimento de que tal voz pertence à morte, figura alegórica que, por fim, revela ter acompanhado o protagonista ao longo do romance:

— Franz, faz duas semanas que você está metido nesse quartinho miserável. Seu senhorio em breve vai te pôr na rua. Você não pode pagar, a mulher não aluga quartos de brincadeira. Se não se controlar, em breve vai ter de ir para um asilo. E aí, e aí? Você não areja seu cubículo, não vai ao barbeiro, está crescendo uma barba castanha, você conseguirá os quinze fênigues em algum lugar. ${ }^{33}$

\footnotetext{
${ }^{31}$ DöBlin. Berlim Alexanderplatz, p.89. A tradução brasileira dessa passagem não corresponde plenamente ao efeito de desintegração da imagem evocada pelo paraíso e pela canção de Hänsel und Gretel, presente no texto original. Uma tradução mais próxima das intenções do autor seria: "Com as mãozinhas, palma, palma, com os pezinhos, pé, peixes, pássaros, dia todo, paraíso. [Mit den Händchen, klapp, klapp, mit den Füßchen trapp, Fische, Vögel, ganzen Tag, Paradies.] (Tradução minha).

${ }^{32}$ DöBlin. Berlim Alexanderplatz; a história de Franz Biberkopf, p.130 e seguintes.

${ }^{33}$ DöBlin. Berlim Alexanderplatz; a história de Franz Biberkopf, p.132.
} 
$\mathrm{Na}$ verdade, a justaposição do texto montado que descreve o matadouro com o trecho que reproduz a voz da morte estabelece entre si uma relação de homologia: assim como o touro que irá ser sacrificado parece aceitar o seu destino, Biberkopf, ao final do romance, só nascerá para uma nova vida no momento em que desistir da ingênua idéia de querer ter o controle de seu destino e aceitar a morte como parte da existência humana.

\section{CONSIDERAÇÕES FINAIS}

A relação entre cinema e literatura, como aponta César Guimarães, sempre formou "um circuito de mão dupla". ${ }^{34}$ Enquanto a literatura emprestou ao cinema, em seus primórdios, um paradigma narrativo - como é o caso de Dickens em relação a Griffith —, o cinema, mais tarde, forneceu à literatura elementos fundamentais para o desenvolvimento de um novo estilo, adequado às transformações do mundo moderno. É nesta segunda via que encontramos Alfred Döblin.

Em princípio, poderia parecer apressada a conclusão de que Döblin realmente tenha sido influenciado exclusivamente pelo cinema ao empregar o princípio estilístico da montagem no romance Berlim Alexanderplatz. Pois, como também destaca César Guimarães, não se pode ter certeza de que autores como John dos Passos, ao compor suas obras - por exemplo, o romance Manhattan transfer (1925) —, realmente tenha extraído a técnica de montagem de filmes que lhe eram contemporâneos. ${ }^{35} \mathrm{Em}$ relação a Döblin, este é um fato que também não podemos afirmar categoricamente. O cinema não foi o único meio não-literário que o influenciou, mas também o rádio e seus novos efeitos acústicos, além das colagens dadaístas de Kurt Schwitters, que, assim como Döblin, também pertencera ao círculo literário Der Sturm.

No entanto, o emprego do conceito de Kinostil, em 1913, a forma como Döblin associa esse conceito a uma postura que lembra os primórdios do cinema, para depois modificá-lo, aproximando-o da linguagem cinematográfica desenvolvida por cineastas como Griffith, Pudovkin e Eisenstein, mesmo que nunca tenha admitido isso, levamnos a crer que as considerações aqui apresentadas demonstram que a relação entre literatura e cinema foi um fator decisivo no modo como Döblin concebeu e pôs em prática a sua "teoria" da obra épica.

\footnotetext{
${ }^{34}$ GUIMARÃEs. Imagens da memória; entre o legível e o visível, p.109.

${ }^{35}$ GuIMARÃEs. Imagens da memória; entre o legível e o visível, p.139.
} 


\section{A B STRACT}

The aim of this article is to present some theoretical aspects developed by the German writer Alfred Döblin in his own conception of the epic work in the "era of the technique". These aspects contribute to a better comprehension of the relationship between Literature and Film in the first decades of the 20th century.

\section{KEY - WORDS}

german literature, montage and film, montage and literature, literature and film, novel of the big city

\section{REFERÊNCIAS BIBLIOGRÁFICAS}

Benjamin, Walter. A obra de arte na era de sua reprodutibilidade técnica (1935/1936). In: Magia e técnica, arte e política; ensaios sobre literatura e história da cultura. 3.ed. Trad. Sérgio Paulo Rouanet. São Paulo: Brasiliense, 1987. p.165-96.

Bernadet, Jean-Claude. O que é cinema. São Paulo: Brasiliense, 2000. (Primeiros Passos, 9).

DöвlIN, Alfred. An Romanautoren und ihre Kritiker. Berliner Programm (1913). In: Schriften zu Ästhetik, Poetik und Literatur. Olten/Freiburg i. Br.: Walter-Verlag, 1989. p.119-23.

DöBlin, Alfred. Berlim Alexanderplatz; a História de Franz Biberkopf. Trad. Lya Luft. Rio de Janeiro: Rocco, 1995.

Döвlin, Alfred. Der Bau des epischen Werks. Die Neue Rundschau, ano 40, n.4. Berlim, abr. 1929. p.527-51.

DöBlin, Alfred. Futuristische Worttechnik. Offener Brief an F. T. Marinetti (1913). In: Schriften zu Ästhetik, Poetik und Literatur. Olten/Freiburg i. Br.: Walter-Verlag, 1989. p.113-9.

Eisenstein, Sergei Mikhailovich. Dickens, Griffith e nós (1943). In: A Forma do Filme. Trad. Teresa Ottoni. Rio de Janeiro: Jorge Zahar, 1990. p.173-216.

EIsenstein, Sergei Mikhailovich. Fora de quadro (1929). In: A Forma do Filme. Trad. Teresa Ottoni. Rio de Janeiro: Jorge Zahar, 1990. p.35-47.

EISENSTEIN, Sergei Mikhailovich. Palavra e imagem (1941). In: O sentido do filme. Trad. Teresa Ottoni. Rio de Janeiro: Jorge Zahar, 1990. p.13-47.

Guimarães, César. Imagens da memória; entre o legível e o visível. Belo Horizonte: Editora UFMG, 1997.

GunNing, Tom. Weaving a narrative; style and economic background in Griffith's biograph films. In: ELSAESSER, Thomas, BARKER, Adam (orgs.). Early cinema: space - frame narrative. London: BFI Publishing, 1992. p.336-47.

Holz, Arno. Die Kunst. Ihr Wesen und ihre Gesetze. In: MEYER, Theo (org.). Theorie des Naturalismus. Stuttgart: Reclam, 1973. p.168-74.

Marinetti, Filippo Tommaso. "Manifesto Técnico" da Literatura Futurista (11 de maio de 1912). In: BERNARDINI, Aurora Fornoni (org.). O futurismo italiano - Manifestos. São Paulo: Perspectiva, 1980. p.81-7. (Debates: arte).

NAZÁrio, Luiz. Contra o cinema conceitual. In: As sombras móveis; atualidade do cinema mudo. Belo Horizonte: Editora UFMG, 1999. p.90-124.

Pudovkin, Vsevolod Illarionovich: Filmtechnique (1929). In: Film technique and film acting. London: Vision Press, 1954.

ZMegac, Viktor. Montage/collage. In: BORCHMEYER, Dieter; ZMEgAC, Viktor (orgs.). Moderne Literatur in Grundbegriffen. Frankfurt a.M.: Athenäum, 1987. p.259-64. 